\title{
Sindrome de intestino irritable en adultos en atención primaria: resumen de la guía NICE
}

\author{
Irritable bowel syndrome in adults in primary care (NICE clinical guideline CG61)
}

Resumido y traducido con autorización del National Institute for Health and Clinical Excellence (NICE)

Disponible en https://www.nice.org.uk/guidance/cg61

\begin{abstract}
Introducción
El Síndrome del Intestino Irritable (SII) es un desorden gastrointestinal crónico con una prevalencia en la población general estimada entre el 10 y el $20 \%$. Esta condición afecta mayoritariamente a personas entre 20 y 30 años de edad, y es dos veces más común en las mujeres que en los hombres. Puede ser dolorosa y debilitante, conducir a sentimientos de ansiedad y depresión, y afectar negativamente la calidad de vida.

Este artículo resume las recomendaciones más recientes del Instituto Nacional de la Salud y Excelencia Clínica del Reino Unido (NICE) sobre el SII en atención primaria.
\end{abstract}

\section{Recomendaciones}

Las recomendaciones del NICE están basadas en revisiones sistemáticas de la mejor evidencia disponible, con consideraciones explícitas sobre la costo-efectividad. En donde la evidencia era mínima, las recomendaciones de la guía original se basaron en las experiencias y opiniones de lo que constituye la buena práctica del grupo de expertos desarrollador de la guía. Los cambios en esta actualización se basan en evidencia sistemáticamente revisada y en evaluaciones de costo-efectividad. Los niveles de evidencia para las recomendaciones se expresan en cursiva y entre corchetes.

\section{Evaluación inicial}

- Considere evaluar la presencia de SII si la persona reporta haber tenido alguno de los siguientes síntomas por al menos seis meses: dolor, molestia, distensión abdominal o cambio en su hábito intestinal.

- Pregunte a todas las personas con síntomas atribuibles a SII si tienen algunos de los indicadores denominados como "bandera roja" y derívelos a centros de atención secundaria para continuar su evaluación si detecta: pérdida de peso inexplicable o no intencional, sangrado rectal, historia familiar de cáncer de colon o cáncer de ovario, cambio en el hábito intestinal (deposiciones más desligadas, más frecuentes, o ambas) que persistan durante más de seis semanas en personas mayores de 60 años.

- Evalúe la presencia de indicadores de tipo "bandera roja" en todas las personas que presentan síntomas compatibles con SII, para derivarlos a centros de atención secundaria en caso de detectar: anemia, masas abdominales, masas rectales o algún signo sugestivo de enfermedad inflamatoria intestinal.

- Considere la posibilidad del diagnóstico de SII sólo si la persona tiene dolor o malestar abdominal que alivia con la defecación o que está asociado con alteraciones en la frecuencia intestinal o en la forma de las heces. El dolor con estas características debe ir acompañado de al menos dos de los siguientes cuatro síntomas: alteración en la evacuación de las heces (estreñimiento, urgencia, evacuación incompleta); hinchazón (más frecuente en las mujeres que en los varones), distensión o tensión abdominal; empeoramiento de los síntomas luego de la ingesta; o presencia de heces mucosas. La presencia de otros síntomas, tales como: letargo, náuseas, dolor de espalda y molestias vesicales son comunes en las personas con SII, y puede ser utilizada para apoyar el diagnóstico.

[Basado en evidencia moderada y baja calidad de ensayos controlados aleatorizados (ECA) y ensayos controlados].

\section{Pruebas de diagnóstico}

- En las personas que cumplan con los criterios diagnósticos de SII, solicite las siguientes pruebas para descartar otros diagnósticos: hemograma completo con plaquetas, eritrosedimentación, proteína C-reactiva y determinación de anticuerpos para la enfermedad celíaca (anticuerpos endomisio o anticuerpos antitransglutaminasa tisular).
-Las siguientes pruebas no son necesarias para confirmar el diagnóstico en personas que cumplen con los criterios diagnósticos de SII: ecografía, recto-sigmoidoscopía, colonoscopía, enema de bario, pruebas de función tiroidea, coproparasitológico, sangre oculta en materia fecal, prueba de hidrógeno espirado (para intolerancia a la lactosa y sobrecrecimiento bacteriano).

[Basado en evidencia moderada y baja calidad de ECA y ensayos controlados].

\section{Consejos para dieta y estilo de vida}

- Proporcione información a las personas con SII que explique la importancia de la auto-ayuda para facilitar el manejo eficaz de su condición, incluyendo consejos sobre el estilo de vida en general, la actividad física, el plan alimentario y la medicación para aliviar los síntomas, como laxantes y antiespasmódicos.

- Estimule a las personas a identificar y aprovechar al máximo su tiempo libre para crear espacios de relajación.

- Proporcione consejo breve y asesoramiento a las personas con niveles bajos de actividad física, para animarlas a aumentar sus niveles de actividad.

- Evalúe los aspectos alimentarios y nutricionales, y proporcione los consejos generales que se enumeran en el cuadro 1.

Cuadro 1. Consejos generales sobre el plan alimentario.

Programar las ingestas a intervalos regulares y con tiempo suficiente para comer en forma pausada.

Evitar saltear las comidas o dejar pasar demasiado tiempo entre ellas.

Beber al menos ocho vasos de líquido diarios, especialmente agua u otras bebidas sin cafeína, como el té de hierbas.

Restringir la ingesta de té y café a tres tazas por día.

Reducir la ingesta de bebidas alcohólicas y gaseosas.

Limitar el consumo de alimentos ricos en fibra (tales como los cereales integrales o las harinas con alto contenido de fibra, los cereales con alto contenido de salvado y los granos enteros como el arroz integral).

Reducir la ingesta de "almidón resistente" (almidón que resiste la digestión en el intestino delgado y alcanza el colon intacto), que se encuentra a menudo en alimentos procesados o pre-cocidos. Limitar las frutas frescas a tres porciones (alrededor de 80 gramos cada una) por día.

Las personas con diarrea deben evitar el sorbitol, un edulcorante artificial que se encuentra en las golosinas y las bebidas sin azúcar (incluyendo la goma de mascar), y en algunos productos para personas con diabetes y/o para adelgazar.

A las personas con meteorismo y distensión abdominal puede serles útil la ingesta de avena y de semillas de lino (hasta un máximo de una cucharada por día).

- Revise el consumo de fibras, ajustándolo (por lo general, reduciéndolo) mientras se monitoriza su efecto sobre los síntomas y disuadiendo el consumo de fibras insolubles, como el salvado. Si se aconseja un incremento en el consumo de fibras, estas deben ser solubles, como el polvo de ispaghula, o reemplazada por alimentos con alto contenido de este tipo de fibras (por ejemplo, avena).

- Asesore a las personas que opten por probar probióticos para que tomen el producto durante al menos cuatro semanas, con la dosis recomendada por el fabricante, mientras se monitoriza su efecto.

- Desaliente el uso de aloe vera para el tratamiento del SII.

- No fomente el uso de acupuntura o reflexología para el tratamiento del SII.

[Todo sobre la base de calidad moderada y baja de ECA y ensayos controlados]. 


\section{Dieta baja en FODMAP}

La dieta baja en FODMAP (de las iniciales en inglés de: oligosacáridos, disacáridos, monosacáridos y polioles fermentables) permite restringir la ingesta de hidratos de carbono de cadena corta, que son mal absorbidos en el intestino delgado y luego fermentados en el intestino grueso. Estos carbohidratos se pueden encontrar en el trigo, algunas frutas y verduras, los frijoles y las legumbres, los edulcorantes artificiales y algunos alimentos procesados. Esta fermentación no es específica para las personas con SII, pero se considera que empeora los síntomas en las personas con esta condición que tienen hipersensibilidad visceral. Si los síntomas del SII persisten mientras se siguen los consejos generales sobre el estilo de vida y el plan alimentario, se puede ofrecer asesoramiento más intensivo sobre esta dieta. Este asesoramiento debe detallar individualmente qué alimentos deben evitarse, y/o proporcionar dietas de exclusión, por ejemplo, una dieta baja en FODMAP (recomendación actualizada). Además, debe ser dado sólo por un profesional sanitario con experiencia en la gestión de la dieta (nueva recomendación). [Basada en ECA de muy baja calidad y ensayos controlados].

\section{Terapia farmacológica}

Antidepresivos

Las decisiones sobre el tratamiento farmacológico deben basarse en la naturaleza y la gravedad de los síntomas. Las siguientes recomendaciones suponen que la elección de fármacos simples o combinados se determina por el/los síntoma/s predominantes/s.

- Considere la prescripción de agentes antiespasmódicos. Éstos se deben tomar según se necesite, junto con consejos sobre la dieta y el estilo de vida.

- Considere la posibilidad de prescribir laxantes para el tratamiento del estreñimiento en las personas con SII, pero desaconseje el uso de lactulosa.

- La loperamida debe ser el agente antiespasmódico de primera elección para el alivio de la diarrea en personas con SII.

- Asesore a las personas con SII sobre cómo ajustar sus dosis de laxantes o agentes antiespasmódicos de acuerdo con la respuesta clínica. Se deberá ajustar la dosis de acuerdo con la consistencia de las heces, con el propósito de conseguir heces suaves, bien formadas (correspondiente a la forma de las heces de tipo 4 en la escala deBristol).

[Todo basado en ECA de moderada, baja y muy baja calidad]. - Considere los antidepresivos tricíclicos (ATC) como segunda línea de tratamiento para las personas con SII si los laxantes, la loperamida o los antiespasmódicos no han ayudado. Estos fármacos se utilizan principalmente para el tratamiento de la depresión, pero se recomiendan aquí sólo por su efecto analgésico. Se deberá empezar con una dosis baja (5 a $10 \mathrm{mg}$ equivalentes de amitriptilina), en una toma por la noche, con revisiones periódicas posteriores. La dosis puede aumentarse, pero por lo general no se necesita exceder los $30 \mathrm{mg}$ diarios. [Sobre la base de ECA de muy baja calidad].

- Considere la prescripción de inhibidores selectivos de la recaptación de serotonina (ISRS) sólo si los ATC son ineficaces. [Basado en la ECA de muy baja calidad].

- Tenga en cuenta los posibles efectos secundarios cuando se ofrece ATC o ISRS para las personas con SII. El seguimiento de las personas que estén tomando cualquiera de estos fármacos por primera vez en dosis bajas para el tratamiento de dolor o el malestar en SII es de cuatro semanas al inicio y luego cada seis a 12 meses. [Basado en ECA de muy baja calidad].

\section{Linaclotida}

Este fármaco, un agonista del receptor de la guanilato-ciclasa-C, pertenece a una clase relativamente nueva de laxantes autorizada para su uso en el SII con estreñimiento moderado a grave, a una dosis de $290 \mu \mathrm{g}$ una vez al día.

- Considere la linaclotida para las personas con SII sólo si: Ios laxantes en dosis óptima o máxima tolerada no han ayudado y la persona ha tenido estreñimiento durante al menos 12 meses. - Realice un seguimiento de las personas que toman linaclotida luego de tres meses.

[Todo sobre la base de ECA de moderada a baja calidad].

\section{Lubiprostona}

Este agonista del canal de cloro (CIC-2), también de una clase relativamente nueva de laxantes, está autorizado para el estreñimiento crónico idiopático cuando los cambios de estilo de vida son inadecuados, a una dosis de $24 \mathrm{mg}$ una vez o dos veces al día. Sin embargo, no se ha hecho ninguna recomendación debido a la falta de evidencia de calidad en su efectividad.

\section{Intervenciones psicológicas}

- Considere la derivación a intervenciones psicológicas (terapia cognitivo-conductual), hipnoterapia, psicoterapia, o una combinación de ellas, en personas que no responden a los tratamientos farmacológicos después de 12 meses y que continúan desarrollando el perfil de síntomas (SII refractario).

[Basado en ECA de moderada a muy baja calidad.]

No se realizó ninguna otra recomendación respecto de intervenciones psicológicas de relajación, la terapia cognitivo-conductual informatizada y la terapia mindfulness debido a la falta de evidencia de calidad sobre su efectividad.

\section{Medicina complementaria y alternativa}

- El uso de la acupuntura no debe ser fomentada como tratamiento del SII. [Sobre la base de moderada a ECA de baja calidad.]

- El uso de la reflexología no debe ser fomentada en el tratamiento de SII. [Basado en un ECA de calidad moderada.]

\section{Seguimiento}

El seguimiento debe ser acordado entre el profesional de la salud y la persona con SII, en base a la respuesta de los síntomas a las intervenciones, y debería forma parte de la revisión anual del paciente. El surgimiento de cualquier signo de bandera roja durante la evaluación y el seguimiento debe generar una mayor investigación o la derivación a cuidados de nivel secundario. [Basado en el consenso de los desarrolladores de la guía; no se identificaron estudios relevantes].

\section{Limitaciones o barreras}

Las barreras potenciales identificadas consisten en que puede haber una disponibilidad insuficiente de profesionales de la salud con experiencia en aconsejar una dieta baja en FODMAP para satisfacer la demanda de esta intervención, y en que la linaclotida tiene un costo superior al de otros laxantes que actualmente se utilizan para tratar el estreñimiento como síntoma predominante del SII.

Fuente de financiamiento: National Institute for Heatlth and Clinical Excellence.

Nota: las guías NICE son desarrolladas para su aplicación dentro del Servicio Nacional de Salud (sigla en inglés, NHS) en el Reino Unido. EI NICE no toma responsabilidad alguna por la traducción al español aquí publicada de la presente guía.

Traducido y adaptado por Romina Amaya (St. Paul's School of English. Buenos Aires, Argentina), de:

Hookway y col. Irritable bowel syndrome in adults in primary care: summary of updated NICE guidance BMJ 2015; 350:h701 y su actualización en abril 2017 disponible en https://www.nice.org.uk/guidance/cg61 (último acceso 11 de julio 2018) 